\title{
Neglected scenario of sanitation in schools of Sunsari district of Nepal: Critical sphere for public health consideration
}

\author{
P Rai $^{1}$, RB Sah ${ }^{1}$, R Rijal ${ }^{2}$, PK Pokharel ${ }^{1}$ \\ School of Public Health and Community Medicine ${ }^{1}$, Department of Orthopaedics ${ }^{2}$, Department \\ B.P. Koirala Institute of Health Sciences, Dharan, Nepal
}

\begin{abstract}
s
Background: Provision of adequate water supply, sanitation facilities, hygiene and waste management in schools reduces the disease burden among children, staff and their families. Every child has equal right to grow in a safe and sound environment. However, levels of water supply, sanitation and hygiene are unacceptable in many schools worldwide. Method: Study included forty schools comprising twenty public and twenty private schools of Sunsari district selected by simple random sampling method. The status of school environment and sanitation were assessed by using observation and interview method using observation checklist, questionnaires and photographs. Result: Two public schools were completely devoid of sanitary facilities though toilet facility was present physically. Students couldn't use toilet due to lack of water in one school due to theft of tube well and septic tank of the toilet was full in another school. Other remaining schools didn't have satisfactory, clean and proper sanitary facilities. Only few schools had convenient hand washing point. Conclusion: Sanitation facilities were in neglected state evidenced by unavailability of sanitation facilities even though that was physically present and the sanitation facilities were in pitiable condition including cleanliness, water supply. All the stakeholders including school management, supervisors, parents, teachers, students should be ready to play vital role on their own. Lack of one toilet affects no. of students and people of surrounding area and raises of risk of soil transmitted diseases so this situation demands attention of authorities and other stakeholders.
\end{abstract}

Key words: Children, school, sanitation facilities

\section{Introduction}

School is a place where children learn the

\section{Address for correspondence}

Mrs. Pramila Rai

Sr. Instructor

School of Public Health and Community Medicine

B.P. Koirala Institute of Health Sciences, Dharan

Email: pramilarai17@hotmail.com values of life. School has significant role to provide theoretical and pragmatic knowledge and skills that are essentially applicable to daily lives which make them healthy and responsible citizen of the country. They learn what is taught in the schools and they retain 
and apply in daily lives what is practiced. School has full exploitation power to bring the change and cultivate healthy way of life in students. So it seems crucial to exemplify itself as an ideal place to learn sanitation and hygienic behavior for students.

Around the world, poor sanitation remains a major threat to development, impacting countries' progress in health, education, gender equity, and social and economic development.

World has dismal facts regarding sanitation facilities. Globally, 2.5 billion people including 840 million children do not use improved sanitation; 1.2 billion, almost a fifth of the world's population, practice open defecation. In rural areas, this is the case for nearly 1 in 3 people. ${ }^{1}$ Nevertheless, the toilet coverage in Nepal has taken a leap from six per cent of the population in 1990 to $62 \%$ in $2013 .^{2}$ and the annual growth rate of sanitation increment currently stands at $1.9 \%$ over the years. The toilet coverage in urban areas is $78 \%$ against the rural coverage of only $37 \%$ implying that there is even big disparity between urban and rural sanitation within the country, although urban areas have other urban specific problems of solid and liquid waste management. The trend analysis shows that if the present trend is continued, the toilet coverage will be only $80 \%$ against the national target of universal coverage by 2017. ${ }^{3}$ A Study in Nepal in 2011 shows that there are water supply facilities only in $76.8 \%$ of the schools and sanitation (toilet) facilities in $80 \%$ schools whereas only $65 \%$ schools have separate toilets for girls. ${ }^{2}$ The studies of the Department of Education and UNICEF have shown $93 \%$ of boys and girls only use school toilets for urinating during schools hours.

It is estimated that $88 \%$ of diarrheal disease is caused by unsafe water supply, and inadequate sanitation and hygiene in developing countries. ${ }^{4} \quad$ The resulting economic cost to individuals and to governments of ill-health and undereducation is at least nine times greater than the cost of addressing this problem. ${ }^{5}$ To make the impact even worse, lack of toilet and urinal in schools has resulted in the dropout rate among girls during their puberty ${ }^{3}$ and it can been inferred that lack of safe, separate and private sanitation can inhibit girls from attending school. It is an obvious fact that women, adolescent girls, children and infants suffer most from inadequate hygiene and sanitation facilities. Poor water, hygiene and sanitation are linked to the two main causes of mortality among children under age five specifically acute respiratory infections and diarrheal diseases. It has been estimated that 1.5 million children die each year from diarrhea. ${ }^{6-8} \mathrm{~A}$ review has estimated that 23\% of all deaths among under 5 in south Asia were caused by diarrheal diseases in the 
year $2000 .^{10}$ In addition repeated diarrheal episodes are a significant underlying cause of malnutrition, leading to weakened immune systems and impaired growth and development. ${ }^{9}$ Diarrhea due to water and sanitation related disease is second leading cause for under five children mortality in Nepal too. ${ }^{11}$ Inadequate sanitation not only harms environmental and human health, but also depresses economic development. Serious health afflictions due to sanitation lead to 4 percent loss of the Gross Domestic Product (GDP) or $\$ 57$ - $\$ 143$ million per year. $^{12}$

Previous literature has shown ample studies regarding the effects of lack of appropriate water facilities, hand washing, and hygiene practices on child health outcomes. Impaired cognitive learning and learning performance are long-term outcomes of the negative effects of infections such as diarrhea, worm infestations, and dehydrations which are largely attributed to poor water, sanitation, and hygiene conditions. $^{13}$ Diarrheal incidences in children during their first few years of life have been shown to limit their growth by about $8 \mathrm{~cm}$ and cause an IQ point reduction when they progress to about 7 or 8 years of age. ${ }^{14}$ Studies have shown that about $75 \%$ of all school absences are illness related ${ }^{15}$ and poor academic and social development, high dropout rates, and reduced learning performance are attributed to school absence in children. ${ }^{16-19}$

Worldwide, lack of access to proper sanitation and improper hygiene is linked to the deaths of 1.5 million children each year and numerous morbidities. ${ }^{20}$ However when we assess and attempt to ensure the quality of schools, we merely review the quality of contents of curriculum and the number of teachers and inevitably their qualifications. We tend to overlook the scenario of its environment and other physical infrastructures which have equal role to facilitate learning of the students. School environment and sanitation are very vital components when school should be evaluated. Clean and friendly environment, Proper sanitation facilities and adequate knowledge of hygiene will result in healthy behavior of children. We tend to neglect such area which influences the student's health and ultimately their learning behavior.

\section{Methods}

We employed the cross sectional study in 2011 to assess the scenario of school sanitation. The study included forty schools including twenty public schools, twenty private schools from Sunsari district of Nepal for equal representation from both types of schools. The schools were selected by random sampling method from the list of schools retrieved from district education office 
located in Sunsari district. Only schools which provided consent to participate in the study, were included. Public Schools are those which have the financial support of the government funded whereas private schools are with full private funding, privately owned and for profit schools.

Data were collected using observation and interview method. The observation checklist, interview schedule and photography were used as a tool for data collection. The observation checklist was designed to include the information regarding sanitary facilities, drinking water facilities, classroom and ground infrastructure and waste management and the interview schedule was designed to elicit information which was not covered by the observation checklist. The tools were validated by experts. We randomly picked one toilet for observation from one school. The minimum standards for sanitation of the school and its environment in India and water, sanitation and hygiene: A minimum standard for low cost setting by WHO were used as the guiding principles to evaluate the appropriateness and adequacy of the various attributes related to school sanitation and environment selected for the study. ${ }^{4}$

Data thus collected were compiled and analyzed using Microsoft excel and SPSS software. Only descriptive statistics like percentages and proportions were derived to deliver finding of the study as required by our objective. Participation of schools in the study was completely voluntary. Confidentiality and anonymity were maintained. Institutional ethical review board approval was obtained from B. P. Koirala Institute of Health Sciences.

\section{Description of toilets}

Pit latrine: The basic components of a pit latrine are the pit, ideally 4-5 meters deep, a cover slab with a hole through which users defecate into the pit and a superstructure, sufficient to ensure privacy and provide protection from the weather.

Ventilated improved pit latrine: It is improved pit latrine with the addition of vent pipe directly attached to substructure with the purpose of venting out the foul smell of feces high up in the atmosphere. Vent pipe at the top is covered with fly screen so that flies don't get contact with the feces.

Pour flush latrine: this type of latrine uses pit for excreta disposal and has special pan which is cast in the floor slab and provides a water seal of 20-30 millimeters. When the latrine is flushed with water, night soil is no longer visible. This ensures that smells can't escape into the shelter and prevents the flies. Cistern- flush latrine: In such type of latrine, the cistern is already connected to the pan so that one needn't pour water with for flushing using other source. 


\section{Results}

Study found all public schools (100\%), all private schools $(100 \%)$ had at least one toilet. However, two public schools (5\%) didn't have functional toilets because of unavailability of water in one school and in another public school; the toilet (septic tank) was already full. Among these two public schools, the toilets in one school were built with an aid of an international organization but the school couldn't maintain the underground water source due to frequent theft of tube well pump from the school periphery so the school authorities closed the school toilets. The dried feces were scattered all over the surface inside the urinals behind the school buildings. We also found that the toilet in one of the public schools was closed and students had to ask the teachers whenever they wanted to use the toilet as the teachers thought that the students will damage the toilet structure.

\section{Table 1: Types of latrine in schools}

\begin{tabular}{|l|l|l|}
\hline Type of latrine & \multicolumn{1}{|c|}{ Private school $(\mathbf{n = 2 0})$} & \multicolumn{1}{|c|}{ Public school $(\mathbf{n = 2 0})$} \\
\hline Pour flush water seal & $19(95 \%)$ & $16(80 \%)$ \\
\hline Cistern flush water seal & NA & $2(10 \%)$ \\
\hline Ventilated improved latrine & NA & $2(10 \%)$ \\
\hline Pit latrine & $1(5 \%)$ & NA \\
\hline
\end{tabular}

$\mathrm{NA}=$ Not available

Pour flush water seal latrines were available in higher number of schools (Table.1). Though there was large no. of water seal type of toilet the trap was filled with fecal matter rather than water due to inadequate supply of water.

Relatively higher number of public schools $(60 \%)$ lay towards bad arms. Fewer private schools (30\%) lay towards bad arms, more schools $(50 \%)$ concentrating on average status $(40 \%)$ had clean toilets followed by private schools and then public schools (25\%). Cleanliness was defined as the surface of the toilet being clean and dry, free of feces and contaminated trashes in the pan and flies inside and outside the toilets. One toilet cubicle from one school was chosen randomly for grading of cleanliness. (Table 2) 
Table 2: Cleanliness of the toilets in schools

\begin{tabular}{|l|l|l|l|l|l|}
\hline \multicolumn{1}{|c|}{ Schools } & \multicolumn{1}{c|}{ Very good } & \multicolumn{1}{c|}{ Good } & \multicolumn{1}{c|}{ Average } & \multicolumn{1}{c|}{ Bad } & \multicolumn{1}{c|}{ Very bad } \\
\hline Public schools & $1(5 \%)$ & $2(10 \%)$ & $5(25 \%)$ & $10(50 \%)$ & $2(10 \%)$ \\
\hline Private schools & $2(10 \%)$ & $2(10 \%)$ & $10(50 \%)$ & $6(30 \%)$ & 0 \\
\hline
\end{tabular}

Higher percentage of the public schools $(60 \%)$ had separate toilet facility for female and male students. To make the situation poorer, very few public (15\%) and private (20\%) schools had suitable, convenient hand washing point beside toilet facilities however soaps were available in hand washing point of two private schools. Whenever we inquired about the availability of soaps then teachers showed the soap in the teacher's office and they reported of shortage of fund for adequate supply of soaps. Few private and public (20\% vs $15 \%$ ) schools had direct supply of water inside toilet facilities and in the remaining schools; students had to fetch water in the bucket themselves from the available drinking water source located outside in the school ground for using toileting purpose. In three public schools (15\%) and in one private school $(5 \%)$ door latches of schools were not functioning. In one private school $(5 \%)$, the roof of the female toilet was open (Table 3)

Table 3: Characteristics of sanitary facilities in schools

\begin{tabular}{|l|l|l|l|}
\hline S.N. & \multicolumn{1}{|c|}{ Characteristics } & Public schools (20) & Private school (20) \\
\hline 1 & Separate toilets for male and female & $12(60 \%)$ & $7(35 \%)$ \\
\hline 2 & Non functioning toilet door latch & $2(10 \%)$ & 0 \\
\hline 3 & Water supply: & $3(15 \%)$ & $4(20 \%)$ \\
& direct water supply & $2(10 \%)$ & 0 \\
& no water available & $15(75 \%)$ & $16(80 \%)$ \\
& water supply outside the toilet & $3(15 \%)$ & $4(20 \%)$ \\
\hline 4 & Hand washing facilities & $17(85 \%)$ & $16(80 \%)$ \\
& Present & $3(15 \%)$ & $1(5 \%)$ \\
\hline 5 & Absent & 0 & $1(5 \%)$ \\
\hline 6 & Non functioning door latches & & \\
\hline
\end{tabular}




\section{Discussion}

We found that students of two public schools were completely devoid of sanitary facilities as toilets in these schools were not used even though the physical structures were present at the time of data collection. Though the other schools had sanitary facilities in use, these weren't perfect and were not free of many blunder and subtle problems.

This study found worst scenario in public schools as compared to private schools as two public schools (10\%) didn't have toilets in use especially coupled with lack of water facilities in schools. Nevertheless the currently existing sanitary facilities in use were insufficient and inappropriately maintained in both types of schools. This finding is also supported by school level educational statistics of Nepal, 2000, showing even worst condition of sanitation facilities in public schools as enumerated that public and community schools, had inadequate latrine coverage with $44.3 \%$ and $47.4 \%$ for boys, with $27.3 \%$ and $34.3 \%$ for girls whereas the coverage for latrine in private schools was high with $91.2 \%$ for boys and $92.3 \%$ for girls. ${ }^{21}$ The country report on water and sanitation also revealed that only 26 per cent of schools in Nepal have proper toilets. ${ }^{22} \mathrm{~A}$ Study conducted in rural India including twenty schools also showed that latrines were grossly inadequate for boys as well as girls in schools of rural India. These schools didn't have any separate urinals. $^{23} \mathrm{~A}$ baseline survey conducted by UNICEF in 1999, in nine sample districts of Uganda; latrines were present in $99 \%$ of schools in the study area. However, only $44 \%$ of the latrines had doors. Only $16 \%$ of schools had latrines assigned to girls only or boys only. Only $20 \%$ of the schools had hand washing facilities next to the latrines. ${ }^{22}$ This data might be considered obsolete to compare the current situation but it presents a neglected scenario of school sanitations in African region.

The provision of separate sanitary facilities for female and male students especially in public schools was very praiseworthy. This availability could be attributed to the focus of national sanitation programmes.

Especially to public schools. Since 2000, Nepal has promoted the school as a model and students as change agents for improving hygiene and sanitation. A School Sanitation and Hygiene Education programme is currently being implemented in more than 1,500 schools in Nepal. ${ }^{12}$

The pour flush water seal type of latrine requires at least 5 liters of water for each flush so there should be adequate water for flush otherwise the trap of pan won't get rid of feces. We also observed this problem in almost all schools, creating nuisance from smell and filth. Hand washing facilities were pitiable in most of the schools. Similar finding was found in Kenya as evidenced by less 
than $2 \%$ of children in schools washed their hands with soap, which was available in less than $5 \%$ of facilities. ${ }^{24}$

Studies have shown that sanitation problem in schools is not the issue of only developing countries, schools in developed countries have also failed to maintain the sanitation facilities based on their own standards. Inadequate numbers of toilet facilities and hand basins, locking of school toilets, unavailability of toilet papers were reported in Schools in London. ${ }^{25,26}$ Many schools were devoid of proper hand washing facilities in schools of New Zealand. ${ }^{27}$

To ensure a healthy school environment that promotes gender equality, all threats to safety, including the physical and social environment, must be considered. ${ }^{28} \mathrm{We}$ also attempted to investigate the safety and security issue in schools and found that some public schools lacked door latches in toilets of schools. It was also revealed that the roof of the female toilet was open in one private school. These kinds of problems might lead to under utilization of existing sanitary facilities ultimately causing discomfort to students and it might lead insecurity especially among female students. Other articles also reported an increase in absenteeism from schools in developing countries during menses due to inadequate sanitation facilities. ${ }^{28}$

\section{Conclusion}

It can be inferred from the study that sanitation facilities in the schools are not satisfactory and students were prevented from using the sanitation facilities due to other conditions even when the sanitation facilities were present in the school even though there is established knowledge that increased access to adequate sanitation facilities in schools of prevention decreases diarrheal and gastrointestinal diseases. ${ }^{29}$ The underlying factor seems to be problem in up to date maintenance. This condition illustrates the failure of school management as well. It depicts negligence of teachers, students, parents and other stakeholders including public health professionals. Such situation demands maintenance of hardware (toilet facilities) and provision of appropriate software comprising health education package focusing on sanitation, hygiene and environment as well.

\section{References}

1. WHO and UNICEF. Joint Monitoring Programme for Water Supply and Sanitation (JMP): Progress on Drinking Water and Sanitation: Special focus on sanitation. New York and Geneva: UNICEF and WHO. 2008; 19.

2. Nepal. Country paper on sanitation. In Fifth South Asian Conference on Sanitation (SACOSAN-V): 22-24 October 2013; Kathmandu. 
http://sacosanv.gov.np/file/file_down/Xg wVt3Sanitation\%20\%20Country\%20Pa per\%20of\%20Nepal.pdf

3. Government of Nepal (GON), Steering committee for national sanitation action. Sanitation and Hygiene Master Plan. 2011.

4. Adams J, Bartram J, Chartier Y, Sims J editors. Water, sanitation and hygiene: standards for schools in low-cost settings. Switzerland: World Health organization. 2009. Available from: www.unicef.org/wash/schools/files/rch_ who_standards_2010.pdf

5. COHRE, WaterAid, SDC and UNHABITAT. Sanitation: A human rights imperative. Geneva; 2008 http://www.cohre.org/sites/default/files/s anitation_report_eng_29_dec_2008.pdf

6. UNICEF. The State of the World's Children 2008: Child survival. New York: UNICEF. 2007; 40.

7. UNICEF and WHO. Diarrhoea: Why children are still dying and what can be done. New York and Geneva: UNICEF and WHO; 2009: 1.

8. Ejemot R I, Ehiri JE, Meremikwu MM, Critchley JA. Hand Washing for Preventing Diarrhoea. Cochrane Database of Systematic Reviews 2008: 1.

9. UNICEF. Field Notes: UNICEF Policy and Programming in Practice. community approaches to total sanitation based on case studies from India, Nepal, Sierra Leone, Zambia. New York: UNICEF. 2009.

10. Morris SS, Black RE, Tomaskovic L. Predicting the distribution of under-five deaths by cause in countries without adequate vital registration systems. Int J Epidemiol 2003; 32: 1041-51.

11. Ministry of Health and Population (MOHP), New ERA, Macro International Inc. Nepal Demographic and Health Survey Report 2006. Kathmandu, Nepal: Ministry of Health and Population (MOHP), New ERA, Macro International Calverton, Maryland. 2007.

12. Adhikari S, Shrestha NL. School Led Total Sanitation: A successful model to promote school and community sanitation and hygiene in Nepal. In: Beyond construction: use by all: a collection of case studies from sanitation and hygiene promotion practitioners in South Asia. London: WaterAid and Delft: IRC International Water and Sanitation Centre. 2008; 113-125. http://www.irc.nl/page/40578

13. Gottfried MA. Evaluating the relationship between student attendance and achievement in urban elementary and middle schools: an instrumental variables approach. The 
American Educational Research Journal 2010; 47(2): 434-465.

14. Guerrant RL, Deboer MD, Moore SR, Scharf RJ, Lima AAM: The Impoverished gut- a triple burden of diarrhea, stunting and chronic disease. Nat Rev Gastroenterol Hepatol 2013; 10 (4): 220-229.

15. Lau CH, Springston EE, Sohn MW, et al. Hand hygiene instruction decreases illness-related absenteeism in elementary schools: a prospective cohort study. BMC Pediatr 2012; 12:52.

16. Bener A, Kamal M, Shanks NJ. "Impact of asthma and air pollution on school attendance of primary school children: are they at increased risk of school absenteeism?" J Asthma 2007; 44(4): 249-252.

17. Kearney CA. An interdisciplinary model of school absenteeism in youth to inform professional practice and public policy. Educational Psychology Review 2008; 20(3): 257-282.

18. Lamdin DJ. Evidence of student attendance as an independent variable in education production functions. Journal of Educational Research 1996, 89(3): 155-162.

19. Reid K. A strategic approach to tackling school absenteeism and truancy: the PSCC scheme. Educational Studies 2003, 29(4): 351-371.
20. Liu L, Johnson HL, Cousens S, Global, regional, and national causes of child mortality: an updated systematic analysis for 2010 with time trends since 2000. Lancet 2012.

21. Rayamajhi M. Nepal- The School Sanitation and Hygiene Education (SSHE) Programme of NEWAH; 2004. Available from: http://www.irc.nl/page/10296

22. UNICEF. Nepal Country Report. Equity in School Water and Sanitation: Overcoming exclusion and discrimination in South Asia. New York: Unicef; 2009. http://www.unicef.org/rosa/WASH_Repo rt_Nepal_\%28Final_draft\%29_17_Dec_ 09.pdf

23. Majra JP, Gur A. School environment and sanitation in rural India. Journal of Global Infectious Disease 2010; 2: 10911. Available from: http://www.jgid.org/text.asp?2010/2/2/1 09/62882

24. Snel M. The Worth of School Sanitation and Hygiene Education (SSHE). Case studies. IRC International Water and Sanitation Centre; 2004. Available from: http://www.irc.nl/page/10296

25. Jewkes RK, o'Conner BH. Crisis in our schools: survey of sanitation facilities in schools in Bloomsbury health district. BMJ 1990; 301(6760): 1085-7. 
26. Croghan EL: A survey of drinking and toilet facilities in local state schools. $\mathrm{Br} \mathrm{J}$ Community Nurs 2002; 7(2): 76-9.

27. Reeves LM, Priest PC, Poore MR. School toilets: facilitating hand hygiene? A review of primary school hygiene facilities in a developed country. J Public Health (Oxf) 2012; 34(4):483-8. doi: 10.1093/pubmed/fds028. Epub 2012 Apr 4.
28. Abrahams N, Mathews S, Ramela P. Intersections of 'sanitation, sexual coercion and girls' safety in schools. Trop Med Int Health 2006; 11(5): 751-6.

29. Jasper C, Le TT, Bartram J. Water and sanitation in schools: a systematic review of the health and educational outcomes. Int $\mathrm{J}$ Environ Res Public Health 2012; 9(8):2772-87. doi: 10.3390/ijerph9082772. 